Original Research Paper

\title{
Public Opinion About Ramadan and Obesity in Egypt
}

\author{
${ }^{1,2}$ Dina Aly Ezzat and ${ }^{1}$ Augustine J. Kposowa \\ ${ }^{1}$ Department of Sociology, University of California Riverside, USA \\ ${ }^{2}$ Assiut University, Egypt
}

\author{
Article history \\ Received: 02-07-2019 \\ Revised: 16-02-2020 \\ Accepted: 23-04-2020 \\ Corresponding Author \\ Dina Aly Ezzat \\ Department of Sociology, \\ University of California \\ Riverside, USA and \\ Assiut University, Egypt \\ E-mail: dezzat@ucr.edu
}

\begin{abstract}
The aim of the study was to investigate the effect of people's perception of Ramadan eating habits and obesity in Egypt. Data were obtained through a paper and pencil cross-sectional survey that was administered to adults aged 18 and above in the Assiut Governorate in Egypt in 2015. The dependent variable was obesity, measured using the body mass index. Multivariate logistic regression models were fitted to the data. Ramadan eating habits were significantly associated with an opinion about obesity ( $\mathrm{AOR}=3.82, \mathrm{CI}=2.91,5.00)$ and individuals that were low in religious orthodoxy experienced odds of obesity that were higher than persons with moderate orthodoxy $(\mathrm{AOR}=1.52, \mathrm{CI}=1.10,2.09)$. The present study has made a significant contribution by exploring how the understanding of and interpretations of religious dogma influence views on obesity. It is expected that future studies will adopt such an approach to studying obesity and other health outcomes.
\end{abstract}

Keywords: Ramadan, Egypt, Family, Fasting, Gastroenterology, Health, Nutrition, Obesity, Religion

\section{Introduction}

Obesity, described as abnormal or excessive fat accumulation is a growing epidemic of global public health significance (WHO, 2015a). It is estimated that in 2008 , over 1.4 billion adults worldwide were overweight and over half a billion were obese. Furthermore, nearly 2.8 million people die annually as a result of being overweight or obese (WHO, 2015a). Data from the World Health Organization show that obesity prevalence nearly doubled between 1980 and 2008. Obesity has also been implicated in mortality from various sources (Kposowa, 2013). In addition to early death, overweight people may be susceptible to many diseases such as heart disease, hypertension, strokes, kidney and pancreatic disorders, cancer, diabetes and rapid fatigue. Moreover, they may find it difficult to breathe after performing basic daily tasks and encounter problems functioning after minor surgical procedures (Musaiger et al., 2011; Al-Ozaira et al., 2015; Faris et al., 2020).

Obesity has considerably increased in the Arab world in the past three decades. Yusuf et al. (2005) observed in the INTERHEART study that the Middle East area had the second highest mean body mass index, second only to North America. It also had the second highest mean waist-to-hip ratio, second to only the South American region. Many reasons have been proposed for the high prevalence of obesity in Arab societies, including globalization and accompanying changes in dietary habits, lifestyle and lack of physical activity (Musaiger et al., 2011). Deterioration in dietary habits have received special attention especially a general move away from eating fruits, vegetables, legumes and whole grains to preference for consuming foods rich in sugar, salt and fat (FAO, 2006; ACN, 2009). One of the major areas of investigation about risk factors for obesity is religion, especially the role of Ramadan. Yet findings on the impact of Ramadan fasting and eating habits on obesity have produced a major puzzle. Some studies report that Ramadan fasting has no effect on body weight (Maislos et al., 1993; El Ati et al., 1995; Akanji et al., 2000; Harder-Lauridsen et al., 2017). Others suggest that Ramadan fasting significantly reduces body weight (Temizhan et al., 2000; Adlouni et al., 1997; 1998). A study by Bakhotmah (2011) observed that contrary to hypothesized study expectations of weight loss, a cohort of Saudi families in Jeddah reported weight gain by the end of Ramadan. Due to contradictory findings in the literature, attention has naturally shifted to explaining reasons for the inconsistencies. One explanation is the relatively small and at times convenience sample sizes used in some studies. Bakhotmah's (2011) study, for example relied on only 173 cases, while a more recent investigation 
(Harder-Lauridsen et al., 2017) employed 10 cases. Large scale population based studies are rare. Another possibility is the over reliance in many studies of before and after designs (for example, 1 week before Ramadan and a week after Ramadan). While there is nothing wrong with the design, it leaves relatively little room for the possibility of moderators during the 29-30 day period that Ramadan typically lasts. For instance during Ramadan, might there be other factors unrelated to diet that could potentially affect obesity? In Egypt in addition to the consumption of high-calorie meals during Ramadan, there is a cultural reluctance to exercise in public places and this affects women more than men (Al-Basal, 2002, 207; Apple, 2010; Eshak et al., 2020). In the present study, we use a large population based study to investigate the impact of beliefs about Ramadan eating and both understanding of and adherence to religious doctrine. The choice of Egypt is justified in that, at over 90 million persons in 2016, it is easily the largest country in the Arab world (CAPMS, 2017). It is also home to some of the most obese and overweight persons in the world. A look at Fig. 1 shows the distribution of the obese population by sex for the world, for Egypt as a whole and for Assiut Governorate, the site of this study.

Data for 2014 show the while the percentage of world population classified as obese was $13 \%$, a corresponding figure for Egypt was over twice that at $28.9 \%$. Women typically tend to experience higher obesity rates than men in Arab countries and this is evident in Fig. 1. The global obesity rate among women was $15 \%$ in 2014 , but
$37.5 \%$ of Egyptian women were obese. For men, the global rate was $11 \%$, while it was $20.3 \%$ in Egypt. We seek to explore public opinion on reasons for the high obesity risk in Egypt, focusing on religion as a major contributing factor. More specifically, the following questions are addressed: (1) do eating habits during Ramadan and related feast days increase obesity risk? (2) Is religious orthodoxy a risk factor for obesity? (3) Are there sex differences in obesity risk among Egyptians? (4) What are the implications of answers to the above questions for research?

\section{Theoretical Framework}

The concept of obesity as a disease may depend on culture, varying from one country to another; it often reflects the viewpoint of members of the community and the role of the disease in their lives (Lotfi, 2007). Some cultural factors guide interpretations of health and disease, which in turn affect health behavior (Ibrahim, 2001). The differential interpretations may link this phenomenon to some important problematic issues, such as religious dogma and the social construction of health. In some communities it is customary not to eat certain types of meat because of traditional or historical practices. Americans often do not eat horse meat while Europeans do and indigenous Indians of Brazil eat some types of ants and insects, while persons in other countries do not (Whiting, 2007). Likewise, some Indians from the subcontinent do not eat beef because cows are supposed to be sacred in Hindu religion (Khatry, 1998).

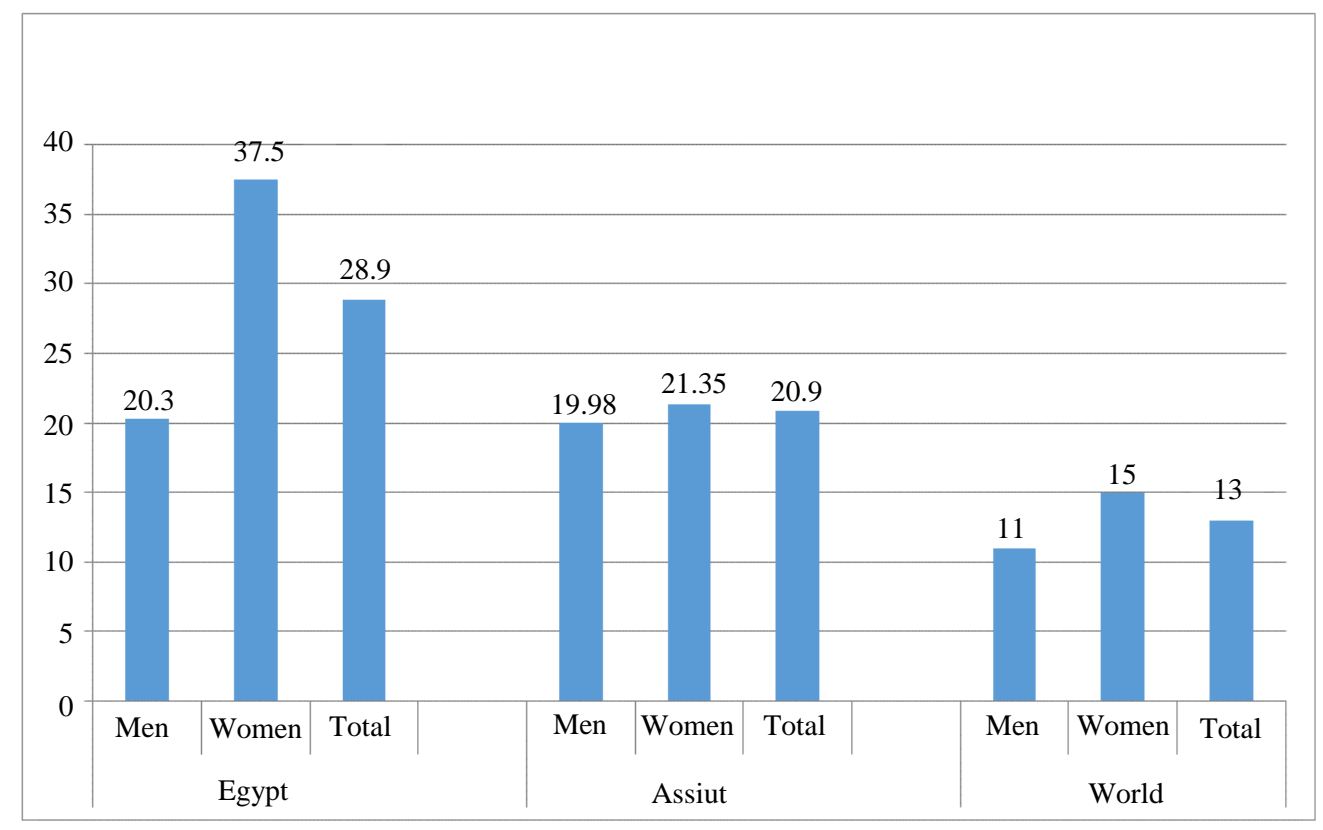

Fig. 1: Percent Obese by Sex, Egypt (2014), Assiut (2015) and World (2014) Source: WHO (2015a); Ezzat and Kposowa (2015) 
There are other eating or dietary habits that may promote obesity, including, for instance, the way parents (especially mothers) raise their children. If children are encouraged or even forced to eat a lot, or are punished if they do not complete their portion of food because waste is frowned upon due to religious teachings or poverty, this may influence childhood obesity. Risk rates also depend on the food system that mothers use and the items purchased for food and its preparation, including the mother's own desires, education, social and cultural environment and beliefs and restrictions against certain foods (Ibrahim and Ibrahim, 2005).

There is now some consensus in the epidemiologic and sociological literature that obesity is associated not only with genetic or biological predispositions, but social factors (Ibrahim, 2001), dissatisfaction with body shape and appearance and reduced self-esteem (Eshak et al., 2020). Social factors include not just individual characteristics, but health behavioral patterns that may be culturally prescribed or expected (Kposowa, 2013). Culturally accepted practices may in turn lead to health outcomes, some of which may not be beneficial to individuals or society at large. Traditions and customs in Egypt and indeed in the Arab world identify overweight women with beauty and if a woman's body is slim it is interpreted as evidence of lack of beauty, poor health and lower socioeconomic status (Al-Mekawy and Al-Jawhry, 1990). Despite scientific evidence to the contrary (El-Mekawy, 2010), Arab traditions believe that women are more able to serve their homes and husbands if they have obese bodies. In addition, Egyptian culture frowns on women who do sports in public, even if they are highly educated. Accordingly, there are more obese Arab women than men, because men are free to run and do sports everywhere and any time (Ali, 2007). Finally obesity may be linked to socio-economic status, which describes the relative position of the individual in a society as a function of education and income levels. Specifically, the rate of obesity is doubled in women of low socio-economic strata compared with those from high social strata (Abdul-Rahman, 1999).

Musaiqar (1992) observed that many important factors affect obesity, including going to fast food restaurants and being with family members or friends at eating time. One disturbing contributor pointed out by investigators is the change in children's toys and games, as children have shifted from moving around to play with their toys to just sitting near electronic games and computers (Musaiqar, 1992). Environmental conditions may impact family members' economic chances as well as their health. In some Arabic communities, people with higher financial and social status usually have huge bodies and weight a feature that has led to the belief that obesity and overweight are indicators of healthy living and being in higher classes. Therefore, the general tendency in these societies is to look on weight gain favorably (Abdul-Aal, 1995).

\section{Ramadan and Weight Gain}

Dining is one of the most pleasant social activities undertaken by humans and in Arab countries, like Egypt, religious events are closely tied to eating with other people, including strangers, household and family members and friends. In fact, excessive eating, especially in the month of Ramadan may play a major role in weight gain. Ramadan is the month when a large group of adults-due to the quality of the food served in this season (including fats and sugary substances)engage in unchecked eating practices. In Ramadan and in keeping with Quranic teaching, healthy adult Muslims must not eat from 4 am until 6 pm (sunrise until sunset) (Muhsin, 1984). This is a rather long period to go without any kind of food or drink. The first meal in the day is served after a very long time of hunger and thirst at almost $6 \mathrm{pm}$. In Egypt and many Arab countries, people often continue to eat until sunrise (4 am) (Muhsin, 1984). There is also elevated sedentary behavior as individuals tend to sit without moving to watch television for extended periods of time. In the Arab world, the most popular free television shows of the year are broadcast between sunset and sunrise during Ramadan (Zeen, 2011).

After the Sunset Prayer at around $6 \mathrm{pm}$, people have 'Iftar' (first meal of the day) while sitting together to watch satellite TV. One covariate of such practice is that individuals tend to feel hungry and consume large amounts of food even though the body might not need it. Furthermore, persons go to sleep late at night for two main reasons: to watch favorite television shows and wait for the last meal at 4 am before fasting for a long time the next day, a practice that likely slows down body metabolism of calories. In addition, during that period (between iftar and the pre-dawn meal), some persons consume lots of snacks such as nuts and oriental sweets. These meals are not required in Islam for observing Ramadan, but have been culturally rooted and passed on through generations in Arab countries. Islam encourages people to make free banquettes for the poor and having dinner with large groups of people often encourages more eating. After that, if they do not have to work the next morning, persons frequently prefer sleeping during the fasting period. Sleeping during the day in Ramadan may lead to weight gain owing to lack of movement and storing of energy (MHSA, 2004; Faris et al., 2020). Due to the various practices outlined above during Ramadan, it is hypothesized that Ramadan is associated with obesity. 


\section{Religious Orthodoxy and Weight Gain}

Religious orthodoxy is understood in this paper as the tendency to which an individual adheres to the tenets of faith, either through a holy book, such as the Bible or Koran, or through interpretations by religious scholars, Imams, ministers, or priests. Despite what religion teaches, adherents may have different understandings or interpretations. Furthermore, there is likely to be variation in the manner individuals practice any religion in their daily life. Some may go for literal interpretations of the written word, while others may not take things strictly as written. Lastly, some adherents may ignore the dogma itself and its interpretations completely and believe that it does not apply to them. Many religions teach what foods to eat and which ones to avoid, how to prepare foods, along with when to fast (Sarri et al., 2006). Adherence to these principles may vary and could in turn affect health and disease, including obesity. In short, although food plays an important role in many religious ritual and teachings, actual practices may differ among individuals, with some following strictly what their religious leaders tell them, while others do not. Investigated here is whether people's interpretation of religious dogma or teaching and its application to their life influence obesity.

\section{Methods}

Data were derived from an epidemiologic cross sectional survey carried out in the Governorate of Asyut, Egypt (Ezzat and Kposowa, 2015). A questionnaire was constructed in Arabic in 2015 and presented to a focus group. The instrument was translated into English to ensure reliability across translations. It was translated again into Arabic and pre-tested on a group of students across disciplines and colleges at Assiut University. The questionnaire was modified based on focus group suggestions; it was pre tested on a different group and further enhancements were made. Permission for the study protocols was obtained from Assiut University Research Ethics Authority. A population-based stratified sampling approach was utilized, employing a sampling frame obtained from the Central Agency for Public Mobilization and Statistics (CAPMAS). The governorate is divided into 15 divisions, so persons were selected in proportion to the division population size. Within a given division, individuals were selected for interview based on 1 out of every 10 households. Fieldwork was completed during a twenty-day period during Ramadan to ascertain people's opinion about fasting and obesity. In each household an adult (18 years old or above) was given the questionnaire in a sealed envelope. The respondent was asked to complete it in a week and give it to a collector (student) in a sealed envelope (provided), who then returned it to a secure office on campus. Given cultural sensitivity about weight and to preserve confidentiality and privacy, respondents were asked not to share or discuss their responses. The population of Assiut was 4245215 in 2015 (CAPMS, 2015) so the targeted sample size was 4,000. The number of returned questionnaires was 3421 , representing a response rate of $85.5 \%$.

\section{Variables and Measurement}

The response variable was obesity, which was measured using the Body Mass Index (BMI). Each respondent was asked to provide their height without shoes in centimeters, as well as their weight in kilograms without shoes. BMI was then calculated as kilograms/centimeters (WHO 2015b). Individuals with BMI values less than 18.5 were considered underweight; those with values 18.5-24.99 were regarded as having normal weight and persons with values 25-29.99 were viewed as over-weight. Individuals that scored 30 or above were classified as obese. To prepare the data for multivariate analysis, individuals scoring 30 or above were coded 1 and all others were coded 0 .

The key explanatory variable was Ramadan eating habits. This was obtained by asking survey respondents the following item: "Do you think that eating habits during Ramadan and special feast days cause weight gain?" Response categories were $1=$ Yes, 2 = No and 3 = Sometimes. The variable was recoded as a series of dummy variables with 1 for yes and 1 for sometimes. Individuals that said no were the reference group for comparison. Note that the survey was about individual opinion or attitude. The second independent variable was Religious orthodoxy, obtained by asking respondents in the survey to respond to the following verse from the Koran: "What do you do after reading this verse of Allah 'Eat and drink but waste not by extravagance, certainly $\mathrm{He}$ (Allah) likes not Al-Musrifun (those who waste by extravagance)'[Al-A'raf: 31]" (Muhsin, 1984). Response categories ranged from $1=\mathrm{I}$ share my food with others (eating with others) (High), $2=\mathrm{I}$ avoid eating too much (Moderate), $3=\mathrm{I}$ eat regularly (Nothing changes in my eating habits (low) and $4=\mathrm{I}$ eat even more food. Based on customary 
interpretations of the verse and in consultation with the Al-Azhar Al-sharif Institute (2015), we divided the responses into low religious orthodoxy, moderate religious orthodoxy, high religious orthodoxy and unorthodox. Individuals responding that they ate regularly and were not driven to extremes by the religious verse (nothing changed in their eating habits) were defined as being low orthodox. Respondents who indicated that they avoid eating too much were classified as moderate orthodox. Persons who stated that they shared their food with others (ate with others) were defined as high orthodoxy; individuals responding that as a result of reading the verse they ate even more were defined as unorthodox. For the purpose of the analysis, the variable was recoded as a series of dummy variables with 1 each for low orthodoxy, high orthodoxy and unorthodox. Persons in the moderate orthodox category constituted the reference group.

\section{Control Variables}

Other variables in the analysis were used as controls. They include sex, with women coded 1 and men used as the omitted group. Educational attainment was derived from the survey question "What is the degree of your education?" The variable was left in its interval form. The lowest value for education was no schooling (coded 0) and the highest value was $\mathrm{PhD}$ (coded 13). Marital status was obtained by asking respondents in the survey: "what is your present marital status?" Response categories were Single/Never married (coded 1), Married (with spouse present (coded 2), Married, no spouse present, (coded 3), Widowed (coded 4), Divorced (coded 5), Separated (coded 6). Marital status was recoded as a series of dummy variables with 1 for the married and 1 for widowed, divorced and separated individuals, combined into one category due to the low number of persons in each separate category. Those single/never married at the time of the survey constituted the reference group. Age was left in its interval format and it ranged from 18 to 77 years. Income was obtained by asking respondents in the survey: "What is your monthly income level?" Response categories (in Egyptian pounds) ranged from 1 for income Less than 600, 2 for income $600-1199,3$ for income 12002000, 4 for income more than 2000 and 5 for Income Unknown. The variable was recoded as a series of dummy variables with 1 for income Less than 600, 1 for income 600-1199, 1 for income more than 2000 and 1 for Income Unknown. Individuals that selected income 1200-2000 were the reference group for comparison. Place of Birth was measured as a dummy variable with 1 for rural and 0 for persons in urban areas who were used as the reference category. Number of Cigarettes was derived from the question "About how many cigarettes do you smoke per day? [Enter number] Enter 0 if you do not smoke." The values ranged from 0 to 60 . The survey had a query about the effect of second hand smoking by asking respondents whether there was a Smoker in household, through the question: "Is there someone around you or living in the same house that is a Smoker?" Response categories were 1 for yes and 2 for no. It was recoded such that individuals answering no were the reference group.

\section{Statistical Estimation}

All statistical calculations were done using SPSS software, version 24 (IBM SPSS, Inc. 2017). Logistic regression models were fitted to the data due to the binary nature of the response variable. On account of missing, illegible, or unknown entries on some of the surveys, not all responses were used. Furthermore, analyses were limited to Muslims, as Ramadan and religious orthodoxy based on the Koran are not applicable to, or appropriate for non-Muslims, so the effective sample size for statistical analyses was 2860 .

\section{Results}

\section{Descriptive Findings}

Descriptive statistics of the variables are shown in Table 1. The mean BMI score for the entire sample was 26.45 ( $\mathrm{SD}=5.78)$, indicating a generally high level of overweight in the Assiut Muslim population. This is confirmed by a further examination of Table 1 where $31 \%$ of the population is overweight (BMI 25 29.99) and 21 percent is obese (BMI 30+). Twenty four percent of the sample affirmed that eating habits during Ramadan contributed to weight gain, while $43 \%$ stated that these practices somewhat contributed to obesity. Thirty percent indicated that Ramadan eating habits did not cause weight gain. As for religious orthodoxy, 54\% scored low; $27 \%$ were in the moderate category and $13 \%$ scored high. Only $3 \%$ were unorthodox. Women comprised $67 \%$ of the sample $(n=$ 1904), while men made up $31 \%(\mathrm{n}=897)$.

In terms of monthly income, the highest percentage of respondents earned less than 600 Egyptian pounds $(49 \%, \mathrm{n}=1416)$. Nearly $18 \%(\mathrm{n}=$ 534) had monthly income in the 600-1199 range; about $16 \%$ reported having income 1200-2000 ( $\mathrm{n}=$ $470), 12 \%$ had income more than $2000(\mathrm{n}=350)$ and $3 \%$ failed to report their earnings $(n=90)$. Forty five percent $(n=1277)$ indicated having a smoker in the 
household, while $52 \%(\mathrm{n}=1405)$ reported there was no smoker. The mean number of cigarettes smoked per day was nearly 1.2 , with wide dispersal as seen in the standard deviation ( $\mathrm{SD}=4.72$ ), with number of cigarettes ranging from 0 to 60 per day. The average educational attainment was $7.78(\mathrm{SD}=2.3)$, which corresponds to 1 or more years of college, but without graduating $(\mathrm{SD}=2.3$ ). The highest reported was 13 , which corresponds to the $\mathrm{PhD}$. Forty one percent of the sample was married $(\mathrm{n}=1184)$ and $55 \%(\mathrm{n}=$ $1572)$ were single/never married. Only 4\% $(n=104)$ were in the divorced/separated and widowed categories combined. For place of birth, 47\% ( $\mathrm{n}=$ 1336) were born in rural places and $49 \%(n=1524)$ stated urban areas. The average age of respondents was 35 years with a rather wide dispersion $(S D=10.88)$.

\section{Multivariate Results}

Relevant results of the effects of Ramadan and religious orthodoxy are presented in Table 2. As may be seen in the table, perceptions about Ramadan eating habits were significantly associated with obesity. Respondents who agreed with the statement that eating habits during Ramadan and other feast days led to wait gain were 3.8 times as likely to be obese as their counterparts that disagreed $(\mathrm{AOR}=3.82,95 \% \mathrm{CI}=2.91$, 5.00). Respondents that agreed somewhat had odds of obesity that were $92 \%$ higher than that of persons that disagreed $(\mathrm{AOR}=1.92, \mathrm{CI}=1.48,2.48)$. High orthodoxy was significantly associated with obesity $(\mathrm{AOR}=1.41, \mathrm{CI}$ $=1.12,1.77$ ) and individuals that were low in religious orthodoxy experienced odds of obesity that were $52 \%$ higher than persons with moderate orthodoxy.

Table 1: Descriptive statistics of the variables

\begin{tabular}{|c|c|c|c|c|c|}
\hline Variables & Number & Mean & SD & Min & $\operatorname{Max}$ \\
\hline$\overline{\mathrm{BMI}}$ & 2860 & 26.45 & 5.785 & 13.00 & 63.00 \\
\hline BMI Classification & 2860 & 02.71 & 0.814 & 1.00 & 4.00 \\
\hline Under Weight $(<18.5)$ & 0053 & 00.19 & & 0.00 & 1.00 \\
\hline Normal Weight (18.5-24.99) & 1316 & 00.46 & & 0.00 & 1.00 \\
\hline Over weight (25-29.99) & 0890 & 00.31 & & 0.00 & 1.00 \\
\hline Obese $(30+)$ & 0601 & 00.21 & & 0.00 & 1.00 \\
\hline \multicolumn{6}{|l|}{ Ramadan } \\
\hline Yes & 0688 & 00.24 & & 0.00 & 1.00 \\
\hline No & 0862 & 00.30 & & 0.00 & 1.00 \\
\hline Sometimes & 1238 & 00.43 & & 0.00 & 1.00 \\
\hline \multicolumn{6}{|l|}{ Religious Orthodoxy } \\
\hline Low & 1536 & 00.54 & & 0.00 & 1.00 \\
\hline Moderate & 0758 & 00.27 & & 0.00 & 1.00 \\
\hline High & 0379 & 00.13 & & 0.00 & 1.00 \\
\hline Unorthodox & 0093 & 00.03 & & 0.00 & 1.00 \\
\hline \multicolumn{6}{|l|}{ Smoker in Household } \\
\hline No & 1405 & 00.52 & & 0.00 & 1.00 \\
\hline Yes & 1277 & 00.45 & & 0.00 & 1.00 \\
\hline Cigarettes smoked per day & 2849 & 01.17 & 4.725 & 0.00 & 60.00 \\
\hline Educational Attainment & 2844 & 07.78 & 2.301 & 1.00 & 13.00 \\
\hline \multicolumn{6}{|c|}{ Monthly Income (Egyptian pounds) } \\
\hline Less than 600 & 1416 & 00.49 & & 0.00 & 1.00 \\
\hline $600-1199$ & 0534 & 00.19 & & 0.00 & 1.00 \\
\hline $1200-2000$ & 0470 & 00.16 & & 0.00 & 1.00 \\
\hline $2000+$ & 0350 & 00.12 & & 0.00 & 1.00 \\
\hline Income Unknown & 0090 & 00.03 & & 0.00 & 1.00 \\
\hline \multicolumn{6}{|l|}{ Marital Status } \\
\hline Married & 1184 & 00.41 & & 0.00 & 1.00 \\
\hline Widowed/Divorced/Sep. & 0104 & 00.04 & & 0.00 & 1.00 \\
\hline Single/Never married & 1572 & 00.55 & & 0.00 & 1.00 \\
\hline \multicolumn{6}{|l|}{ Place of Birth } \\
\hline Rural & 1336 & 00.47 & & 0.00 & 1.00 \\
\hline Urban & 1524 & 00.49 & & 0.00 & 1.00 \\
\hline Age & 2806 & 35.07 & 10.884 & 18.00 & 77.00 \\
\hline \multicolumn{6}{|l|}{ Sex } \\
\hline Male & 0897 & 00.31 & & 0.00 & 1.00 \\
\hline Female & 1904 & 00.67 & & 0.00 & 1.00 \\
\hline
\end{tabular}


Table 2: Results of the effect of Ramadan and religious orthodoxy on obesity

\begin{tabular}{|c|c|c|c|c|}
\hline Covariates & $\beta$ & Wald & AOR & $95 \%$ CI. \\
\hline \multicolumn{5}{|l|}{ Ramadan } \\
\hline No & & Reference & & 1.00 \\
\hline Yes & $1.339 * * *$ & 94.048 & 3.82 & $2.911,5.002$ \\
\hline Sometimes & $0.654 * * *$ & 24.923 & 1.92 & $1.488,2.487$ \\
\hline \multicolumn{5}{|l|}{ Religious orthodoxy } \\
\hline Moderate & Reference & & 1.00 & \\
\hline Low & $0.421 * *$ & 6.662 & 1.52 & $1.106,2.094$ \\
\hline High & $0.341 * *$ & 8.385 & 1.41 & $1.117,1.773$ \\
\hline Unorthodox & 0.019 & 0.004 & 1.02 & $0.545,1.907$ \\
\hline \multicolumn{5}{|l|}{ household smoker } \\
\hline No & Reference & & 1.00 & \\
\hline Yes & -0.068 & 0.451 & 0.93 & $0.765,1.14$ \\
\hline Number of Cigarettes & $-0.0401 * *$ & 8.922 & 0.96 & $0.936,0.986$ \\
\hline \multicolumn{5}{|l|}{ Place of Birth } \\
\hline Urban & Reference & & 1.00 & \\
\hline Rural & $-0.344 * * *$ & 11.06 & 0.71 & $0.579,0.868$ \\
\hline \multicolumn{5}{|l|}{ Marital status } \\
\hline Single/Never married & Reference & & 1.00 & \\
\hline Married & $1.029 * * *$ & 63.8 & 2.80 & $2.174,3.602$ \\
\hline Widowed/Div/Separated & $0.843^{* * *}$ & 11.055 & 2.32 & $1.413,3.817$ \\
\hline Education & $-0.103 * * *$ & 22.709 & 0.91 & $0.864,0.941$ \\
\hline \multicolumn{5}{|l|}{ Monthly Income (EGP) } \\
\hline $1200-2000$ & Reference & & 1.00 & \\
\hline Less than 600 & $-0.404 * *$ & 8.291 & 0.67 & $0.507,0.879$ \\
\hline $600-1199$ & -0.269 & 2.871 & 0.76 & $0.56,1.043$ \\
\hline $2000+$ & -0.249 & 2.002 & 0.78 & $0.552,1.101$ \\
\hline Income Unknown & -0.622 & 2.967 & 0.54 & $0.266,1.089$ \\
\hline \multicolumn{5}{|l|}{ Sex } \\
\hline Male & Reference & & 1.00 & \\
\hline Female & 0.027 & 0.065 & 1.03 & $0.834,1.267$ \\
\hline Age & 0.009 & 2.425 & 1.01 & $0.998,1.02$ \\
\hline Constant & -1.832 & & & \\
\hline LRS & $325.92 * * *$ & & & \\
\hline df & 17 & & & \\
\hline Nagelkerke $\mathrm{R}^{2}$ & 0.172 & & & \\
\hline Events/Total & $581 / 2781$ & & & \\
\hline
\end{tabular}

Note: ***Significant at $p<0.001 ; * *$ significant at $p<0.01$; Significant at $p<0.05$. AOR $=$ Adjusted Odds ratio

Presence of a household smoker was not significantly associated with obesity, but number of cigarettes smoked per day reduced the odds of obesity (AOR $=0.96, \mathrm{CI}=0.93,0.98)$. Respondents that were born in rural areas were $29 \%$ ([OR-1]*100) were less likely to be obese than their counterparts born in the urban environment $(\mathrm{AOR}=0.71, \mathrm{CI}=0.57,0.86)$. The married (AOR $=2.80)$ and the divorced/separated/widowed $(\mathrm{AOR}=2.32)$ had much higher odds of obesity than single/never married persons. Higher levels of education on the whole reduced the odds of obesity $(\mathrm{AOR}=0.91, \mathrm{CI}=0.86$, 0.94). No major differentials were observed in obesity by income levels, except that those making less than 600 pounds per month were $33 \%$ less likely to be obese than individuals making 1200 to 2000 per month. No sex disparities were observed in the multivariate analyses; similarly, no significant age differences were found.

\section{Results based on Stratification by Sex}

Although no significant differentials were observed for the entire sample, it was decided to stratify sex in order to identify whether there are variables on which the two groups might differ. Relevant results of the effects of the covariates broken down by sex are shown in Table 3. As may be observed, male respondents that attributed obesity to Ramadan eating practices were nearly 5.6 times as likely to be obese than those who did not attribute 
obesity to Ramadan $(\mathrm{AOR}=5.57, \mathrm{CI}=3.37,9.19)$. Men who said that Ramadan somewhat contributed to weight gain were over 2 times as likely to be obese as their counterparts that disagreed. When women were considered, the odds of obesity among those attributing weight gain to Ramadan was over 3 times higher than the odds of those that did not blame the festival. Women who said that Ramadan somewhat caused weight gain were $80 \%$ more likely to be obese than their counterparts who disagreed. Findings on religious orthodoxy were rather interesting, as there were no differences among men, but substantial disparities were found among women. Women with low religious orthodoxy had odds of obesity that were 57\% more elevated than those women with moderate religious orthodoxy $(\mathrm{AOR}=1.57, \mathrm{CI}=1.06,2.34)$. Similarly, women with high religious orthodoxy experienced obesity odds that were 53\% higher than those of women in the moderate religious orthodoxy group.

Cigarette smoking had no effect on obesity in men, but it significantly reduced the odds of obesity in women ( $\mathrm{AOR}=0.96, \mathrm{CI}=0.92,0.99)$. Educational attainment reduced obesity in both groups and differentials in marital status were also observed in both. Finally, whereas increasing age had no impact on obesity in men, it elevated obesity risk in women.

Table 3: Effects of Ramadan and religious orthodoxy on obesity: Stratification by sex

\begin{tabular}{|c|c|c|c|c|c|c|c|c|}
\hline Covariates & Male $\beta$ & Female Wald & AOR & $95 \%$ CI. & $\beta$ & Wald & AOR & $95 \%$ CI. \\
\hline \multicolumn{9}{|l|}{ Ramadan } \\
\hline No & Reference & & 1.000 & & Reference & & 1.00 & \\
\hline Yes & $1.718 * * *$ & 45.23 & 5.570 & $3.378,9.192$ & $1.192 * * *$ & 51.16 & 3.29 & $2.377,4.569$ \\
\hline Sometimes & $0.852 * * *$ & 11.65 & 2.340 & $1.437,3.821$ & $0.588 * * *$ & 14.31 & 1.80 & $1.328,2.443$ \\
\hline \multicolumn{9}{|l|}{ Religious } \\
\hline Orthodoxy & Reference & & 1.000 & & Reference & & 1.00 & \\
\hline \multicolumn{9}{|l|}{ Moderate } \\
\hline Low & 0.389 & 1.92 & 1.480 & $0.851,2.56$ & $0.453 * *$ & 5.07 & 1.57 & $1.061,2.334$ \\
\hline High & 0.169 & 0.66 & 1.180 & $0.788,1.778$ & $0.428 * * *$ & 8.78 & 1.53 & $1.156,2.036$ \\
\hline Unorthodox & -0.168 & 0.09 & 0.850 & $0.283,2.531$ & 0.082 & 0.04 & 1.09 & $0.503,2.345$ \\
\hline \multicolumn{9}{|l|}{ Household Smoker } \\
\hline No & Reference & & 1.000 & & Reference & & 1.00 & \\
\hline Yes & -0.158 & 0.75 & 0.850 & $0.597,1.22$ & -0.016 & 0.02 & 0.98 & $0.772,1.254$ \\
\hline Number of & -0.032 & 2.51 & 0.967 & $0.93,1.008$ & $-0.044 * *$ & 6.03 & 0.96 & $0.925,0.991$ \\
\hline \multicolumn{9}{|l|}{ Cigarettes } \\
\hline \multicolumn{9}{|l|}{ Place of Birth } \\
\hline Urban & Reference & & 1.000 & & Reference & & 1.00 & \\
\hline Rural & $-0.364 * *$ & 3.96 & 0.690 & $0.485,0.995$ & $-0.340 * * *$ & 7.29 & 0.71 & $0.556,0.911$ \\
\hline \multicolumn{9}{|l|}{ Marital Status } \\
\hline $\begin{array}{l}\text { Single/Never } \\
\text { married }\end{array}$ & Reference & & 1.000 & & Reference & & 1.00 & \\
\hline Married & $1.062 * * *$ & 20.97 & 2.890 & $1.836,4.556$ & $1.013 * * *$ & 42.04 & 2.75 & $2.028,3.741$ \\
\hline Widowed/Divorced & $1.193 * * *$ & 7.69 & 3.300 & $1.419,7.664$ & $0.645^{* *}$ & 4.09 & 1.90 & $1.02,3.56$ \\
\hline \multicolumn{9}{|l|}{ /Separated } \\
\hline Education & $-0.084 * *$ & 4.45 & 0.920 & $0.851,0.994$ & $-0.111 * * *$ & 18.22 & 0.89 & $0.85,0.942$ \\
\hline \multicolumn{9}{|l|}{ Income (EGP) } \\
\hline $1200-2000$ & Reference & & 1.000 & & Reference & & 1.00 & \\
\hline Less than 600 & -0.272 & 1.23 & 0.760 & $0.471,1.232$ & $-0.481 * * *$ & 7.85 & 0.62 & $0.441,0.865$ \\
\hline $600-1199$ & -0.283 & 0.95 & 0.750 & $0.427,1.329$ & -0.276 & 2.09 & 0.76 & $0.523,1.103$ \\
\hline $2000+$ & -0.036 & 0.01 & 0.960 & $0.525,1.771$ & -0.365 & 2.88 & 0.69 & $0.456,1.058$ \\
\hline Unknown & -0.593 & 1.17 & 0.550 & $0.188,1.621$ & -0.596 & 1.54 & 0.55 & $0.215,1.412$ \\
\hline Age & -0.001 & 0.01 & 1.000 & $0.979,1.02$ & $0.013 *$ & 3.92 & 1.01 & $1.00,1.027$ \\
\hline Constant & $-1.832 * * *$ & 9.24 & 0.160 & & $-1.849 * * *$ & 21.51 & 0.16 & \\
\hline LRS & $119.550^{* * * *}$ & & & & $215.386^{* * *}$ & & & \\
\hline df & 16 & & & & 16 & & & \\
\hline Nagelkerke $\mathrm{R}^{2}$ & 0.19 & & & & 0.17 & & & \\
\hline Events/total & $188 / 757$ & & & & $393 / 1854$ & & & \\
\hline
\end{tabular}

\footnotetext{
***Significant at $p<0.001 ; * *$ Significant at $p<0.01 ; *$ significant at $p<0.05 ;$ AOR $=$ Adjusted Odds ratio
} 


\section{Discussion}

This study examined public opinion or views about the effects of Ramadan and Religious Orthodoxy on odds of obesity in Egypt using a large representative sample of a major governorate, Assiut. Data analysis revealed that Ramadan is strongly associated with obesity, in that respondents agreeing with the statement that eating habits during Ramadan caused weight gain were much more likely to be obese than persons disagreeing. A legitimate question to address is how and why Ramadan might elevate obesity risk.

A plausible explanation is that Ramadan may actually not be a fasting season in the sense of people going without food, but a religious festival whereby individuals merely shift eating from regular hours of the day to some other time, typically night. Given that a lot of food is eaten when persons break their fast and also a lot is eaten before they begin fasting the next day, food, often eaten in large quantities may be stored by the body and without much mobility, metabolism is slowed at night, which may in part contribute to weight gain. This may be one reason why Ramadan is associated so strongly with obesity and this interpretation is supported by a 15year survey of the literature and meta-analysis on the impact of Ramadan on diurnal intermittent fasting by Faris et al. (2020). We hasten to add that analyses are based on public opinion or perceptions, which may not always be based in reality.

A related explanation is the lack of specificity about foods that are forbidden to be eaten during Ramadan. With the possible exception of pork, Muslims can eat any kind of food between sunset and sunrise; there are no limits on quantity of food items (Sadiya et al., 2011). It is plausible that fear of hunger during fasting in the day may inadvertently encourage individuals to eat much more exorbitantly at night before daybreak and in the process gain weight. The findings about weight gain due to Ramadan are consistent with those of Bakhotmah (2011) who predicted weight loss, but instead found weight gain among 173 final year undergraduate nutrition female students across Jeddah. That study additionally noted that expenditure on food increased substantially during the month of Ramadan and eating frequency also increased. Results here showing a link between Ramadan and weight gain are, however, at variance with those observed by Sadiya et al. (2011) in their study of 19 patients with metabolic syndrome in the United Arab Emirates. They observed that following Ramadan, patients lost weight and reduced their waist circumference. Their findings must be interpreted with care, however, in that the authors admitted encouraging participants to adopt healthy life style changes during Ramadan.
Results of the present investigation are also inconsistent with those noted in the study by Harder-Lauridsen et al. (2017) who reported a minor decrease in body weight and BMI in a sample of ten healthy lean men in a nonrandomized crossover design to test for the effects of a Ramadan model of intermittent fasting. There are many inconsistent findings in past research on the impact of Ramadan on weight, but most present evidence to suggest that even if there is modest weight loss, it is reversed relatively quickly following Ramadan. In a systematic review and meta-analyses of past work on Ramadan and weight, Sadeghirad et al. (2012) reported that fasting in Ramadan led to a significant weight loss ($1.24 \mathrm{~kg}$; CI $=-1.60,-0.88$ ), but this was gradually reversed to what it was before Ramadan, with weight loss lasting no more than two weeks.

Findings of this research show that religious orthodoxy is significantly associated with obesity, especially among women. It may well be that people's interpretation of religious dogma or teaching and its application to their life may impact health outcomes, in this case obesity. To the best of the authors' knowledge, this is the first report to explore this association. Prior to studies have found that religiosity and spirituality were protective factors for both mental and physical health (Koenig et al., 2004; Lawler-Row and Elliott, 2009; Reeves et al., 2012). Most studies to date have, however, found no significant association between religiosity, spirituality and obesity (Ellis and Biglione, 2000; Roff et al., 2005; Gillum, 2006; Bruce et al., 2016). It is plausible that for obesity research, emphasis might be better placed not so much on variables such as frequency of religious attendance, frequency of prayer, how close adherents feel close God or other measures that have been used in the past to capture religion, but how individuals understand and apply religious teachings. Adherents may read the same passage from a sacred text or even listen to the same sermon, but come up with remarkably different interpretations as to how it is applicable to them. Given that the three monotheistic religions have admonitions about eating and dietary habits, a breakthrough in obesity and health research in general might be accomplished by concentrating on how believers comprehend and apply religious exultations. For example, in Christianity, especially Roman Catholicism, gluttony (eating in excess) is considered one of the Seven Deadly Sins (Prose, 2003). It would be interesting to explore believers' understanding of this concept and whether it impacts eating and dietary habits and weight management.

This study is not without limitations. First, it was based on only one governorate in Egypt, Assiut, which happens to be rural. Thus, caution should be used in applying findings to the entire country. Relatedly, the questionnaire used did not have an item to measure 
current pregnancy and/or assessment of the menstrual cycle. It is thus likely that findings have underestimated the true extent of obesity among women and these omissions partly explain why no significant differences were observed between men and women. We also did not explore self-esteem, especially among young women, which could play in role in reducing obesity. A recent study by Eshak et al. (2020) based on interviews of 1408 young women at Minia University (Egypt) showed strong associations between appearance and body shape dissatisfaction and self-esteem among adolescent Egyptian females.

The second limitation is that the question on Ramadan eating habits was based on individual opinion or perception. We are not implying a causal link but simply trying to ascertain individual thoughts or opinions as to whether they believed eating was associated with weight gain in Ramadan. Ideally, it would have been better to have a before-and-after design, but this was not possible. We thus consider this study as exploratory. The third limitation is that analyses of the association between Ramadan and obesity are based on perceptions or opinion. We did not directly measure Ramadan, but opinion about Ramadan. Therefore, the reader is advised not to make causal associations. Obesity was measured directly, but this took placed after the fasting season. Perhaps ideally, an experimental design would have been more appropriate, but given such a large sample, this approach was simply not feasible.

Despite the above limitations, this study fills an important gap in the literature, as there have been relatively few population based studies to investigate the association of perceptions of Ramadan and obesity. Much of past work used experimental designs and small samples in which individuals were weighed before and after Ramadan, with the general conclusion that even if modest weight reductions were observed, participants regained weight shortly after Ramadan. The present study was conducted during the fasting holy season itself while individuals were fully aware of their eating habits; it was based on individual beliefs about whether the festival contributed to weight gain. The findings further fill an important gap in the existing literature about religion and obesity. Most prior work relied on measuring religion in terms of frequency of religious attendance and spirituality. The present study has made a significant advance by exploring how understanding of and interpretations of religious dogma influences obesity. It is expected that future studies will adopt such an approach in studying obesity and other health outcomes.

\section{Acknowledgment}

The first author would like to thank the Department of Sociology, University of California Riverside for providing her space to conduct this research and write the first draft of the paper. We also express gratitude to Assiut University, Egypt for giving Dr. Aly permission to conduct the survey.

\section{Informed Consent}

Informed consent was obtained from all individual participants included in the study.

\section{Funding}

Funding information is not applicable, as no funding was received.

\section{Authors Contributions}

All authors equally contributed in this work.

\section{Conflict of Interest}

The authors declare that they have no conflict of interest.

\section{Ethical Approval}

The study protocols were written by the authors and submitted for approval to the Assiut University Ethics Review Board. The protocols, including questionnaires were also submitted to the Central Agency for Public Mobilization and Statistics, the sole body in Egypt that is responsible for approval of all data collection. All procedures performed in this study involving human participants were in accordance with the ethical standards of Assiut University and the Central Agency for Public Mobilization and Statistics, Cairo, Egypt and with the 1964 Helsinki Declaration.

\section{References}

Abdul-Aal, M., 1995. Obesity and endocrine diseases: Causes and prevention. Al-Ahram Foundation, Cairo, Egypt.

Abdul-Rahman, M., 1999. Awareness of psychological and mental diseases. Dar Quba, Cairo, Egypt.

Adlouni, A., N. Ghalim, A. Benslimane, J.M. Lecerf and R. Saile, 1997. Fasting during Ramadan induces a marked increase in high density lipoprotein cholesterol and decrease in low density lipoprotein cholesterol. Annals Nutrit. Metabolism, 41: 242-249. DOI: $10.1159 / 000177999$ 
Adlouni, A., N. Ghalim, R. Saile, N. Had and H.J. Parra et al., 1998. Beneficial effect on serum APO AI, APO B and LP AI levels of Ramadan fasting, Clin. Chimica Acta, 271: 179-189.

DOI: $10.1016 / \mathrm{S} 0009-8981(97) 00245-3$

Akanji, A.O., O.A. Mojiminiyi and N. Abdella, 2000. Beneficial changes in serum APO A-1 and its ratio to APO B and HDL in stable hyperlidaemic subjects after Ramadan fasting in Kuwait. Eur. J. Clin. Nutrit., 54: 508-513. DOI: 10.1038/sj.ejcn.1601047

Al-Azhar Al-sharif Institute 2015. http://www.azhar.eg/splash.html

Al-Basal, A., 2002. Obesity is a disease of the times. Cultural J., 56: 307-309.

Ali, N., 2007. Psychological causes of obesity in women in the Arab countries. Civilized Dialogue.

Al-Mekawy, A. and M. Al-Jawhry, 1990. Medical sociology. Dar Al-Maarifa, Alexandria, Egypt.

Al-Ozaira, E., J. Al-Kandari, D. Al-Haqqan, O. Al-Harbi and Y. Masters et al., 2015. Obesity surgery and Ramadan: A prospective analysis of nutritional intake, hunger and satiety and adaptive behaviours during fasting. Obesity Surgery, 25: 523-529.

DOI: $10.1007 / \mathrm{s} 11695-014-1373-0$

Apple, K., 2010. The ability to self-assessment, control and understanding the concepts of health education in a sample of obesity people in the Kuwaiti society on some variables. J. Faculty Educ., 20: 355-389.

Bakhotmah, B.A., 2011. The puzzle of self-reported weight gain in a month of fasting Ramadan among a cohort of Saudi families in Jeddah, Western Saudi Arabia. Nutrit. J., 10: 1-8.

DOI: 10.1186/1475-2891-10-84

Bruce, M.A., B.M. Beech, D.M. Griffith and R.J. Thorpe, 2016. Spirituality, religiosity and weight management among African American adolescent males: The Jackson Heart KIDS Pilot Study. Behavi. Med., 42: 183-189. DOI: 10.1080/08964289.2015.1121133

ACN, 2009. Nutrition situation in the Arab countries Manama. Bahrain.

CAPMS, 2015. Central Agency for Public Mobilization and Statistics. The Egypt statistical abstract. CAPMAS, Cairo.

CAPMS, 2017. Central agency for public mobilization and statistics. Egypt statistics.

El Ati, J., C. Beji and J. Danguir, 1995. Increased fat oxidation during Ramadan fasting in healthy women: An adaptive mechanism for body-weight maintenance. Am. J. Clin. Nutrit., 62: 302-307. DOI: 10.1093/ajcn/62.2.302

Ellis, L. and D. Biglione, 2000. Religiosity and obesity: Are overweight people more religious? Personality Individual Differences, 28: 1119-1123. DOI: $10.1016 / \mathrm{S} 0191-8869(99) 00161-0$
El-Mekawy, A., 2010. Medical anthropology: Theoretical studies and field research. Cairo University Press, Cairo, Egypt.

Eshak, E., S. Ghazawy, E. Ramadan and M.E. Sameh, 2020. Sociocultural attitudes toward appearance and body shape dissatisfaction in adolescent Egyptian females: Association and moderators. Health Promot. Int. DOI: 10.1093/heapro/daz126

Ezzat, D. and A.J. Kposowa, 2015. Some cultural covariates of obesity in Egypt: An epidemiologic investigation [computer data file]. Department of Sociology, Assiut University.

FAO, 2006. Technical consultation on national foodbased dietary guidelines. World Health Organization Regional Office, Cairo.

Faris, M.A.I.E., H.A. Jahrami, J. Alsibai and A.A. Obaideen, 2020. Impact of Ramadan diurnal intermittent fasting on the metabolic syndrome components in healthy, non-athletic Muslim people aged over 15 years: A systematic review and metaanalysis. Brit. J. Nutrit., 123: 1-22.

DOI: $10.1017 / \mathrm{S} 000711451900254 \mathrm{X}$

Gillum, R.F., 2006. Frequency of attendance at religious services, overweight and obesity in American women and men: The 3rd national health and nutrition examination survey. Annals Epidemiol., 16: 655-660. DOI: 10.1016/j.annepidem.2005.11.002

Harder-Lauridsen, N.M., A. Rosenberg, F.B Benatti, J.A. Damm and C. Thomsen et al., 2017. Ramadan model of intermittent fasting for $28 \mathrm{~d}$ had no major effect on body composition, glucose metabolism, or cognitive functions in healthy lean men. Nutrition, 37: 92-103. DOI: 10.1016/j.nut.2016.12.015

IBM SPSS, Inc. 2017. SPSS 24 [computer software]. IBM Corporation, Chicago.

Ibrahim, A. and M. Ibrahim, 2005. Medical anthropology. University Knowledge House, Alexandria, Egypt.

Ibrahim, M., 2001. Anthropology: Entries and applications. Dar Al-Maarefah, Alexandria, Egypt.

Khatry, P., 1998. Harris and the sacred cow: A critique on Marvin Harris' materialistic theory on the Hindu India' holiest animal. Tribhuvan Univ. J., 21: 1-8. DOI: $10.3126 /$ tuj.v21i2.4570

Koenig, H.G., L.K. George, P. Titus, 2004. Religion, spirituality and health in medically ill hospitalized older patients. J. Am. Geriatrics Society, 52: 554-562. DOI: 10.1111/j.1532-5415.2004.52161.x

Kposowa, A.J., 2013. Mortality from Diabetes by Hispanic Groups: Evidence from the US national longitudinal mortality study. Int. J. Populat. Res. DOI: $10.1155 / 2013 / 571306$

Lawler-Row, K.A. and J. Elliott, 2009. The role of religious activity and spirituality in health and wellbeing of older adults. J. Health Psychol., 14: 43-52. DOI: $10.1177 / 1359105308097944$ 
Lotfi, S., 2007. Disability culture: A socio anthropological study on the families of disabled children in Sohag.

Maislos, M., N. Khamaysi, A. Assali, Y. Abou-Rabiah and I. Zvili et al., 1993. Marked increase in plasma high density lipoprotein cholesterol after prolonged fasting during Ramadan. Am. J. Clin. Nutrit., 57: 640-642. DOI: 10.1093/ajcn/57.5.640

MHSA, 2004. Ministry of health of Saudi Arabia, the General Department of Nutrition. Nutrit. Health Magaz., 42: 1-5.

Muhsin, M., 1984. The noble Qur'an. King Fahd Complex, Madinah, K.S.A.

Musaiger, A.O., H.M. Al-Hazzaa, A. Al-Qahtani, J. Elati and J. Ramadan et al., 2011. Strategy to combat obesity and to promote physical activity in Arab countries. Diabetes Metabolic Syndrome Obesity Targets Therapy, 4: 89-97. DOI: $10.2147 / \mathrm{DMSO} . S 17322$

Musaiqar, A.A., 1992. Food and nutrition. Academia, Cairo City, Egypt.

Prose, F., 2003. Gluttony: The Seven Deadly Sins. 1st Edn., Oxford University Press, New York, ISBN-10: 0199760683, pp: 128.

Reeves, R.R., C.E. Adams, P.M. Dubbert, D.M. Hickson and S.B. Wyatt, 2012. Are religiosity and spirituality associated with obesity among African Americans in the Southeastern United States (the Jackson Heart Study)? J. Relig. Health, 51: 32-48. DOI: 10.1007/s10943-011-9552-y

Roff, L.L., D.L. Klemmack, M. Parker, H.G. Koenig and P. Sawyer-Baker et al., 2005. Religiosity, smoking, exercise and obesity among southern, communitydwelling older adults. J. Applied Gerontol., 24: 337-354. DOI: 10.1177/0733464805278132
Sadeghirad, B., S. Motaghipisheh, F. Kolahdoz, M.J. Zahedi and A.A. Haghdoost, 2012. Islamic fasting and weight loss: A systematic review and metaanalysis. Public Health Nutrit., 17: 396-406. DOI: $10.1017 / \mathrm{S} 1368980012005046$

Sadiya, A., S. Ahmed, H.H. Siddieg, I.J. Babas and M. Carlsson, 2011. Effect of Ramadan fasting on metabolic markers, body composition and dietary intake in Emiratis of Ajman (UAE) with metabolic syndrome. Diabetes Metabolic Syndrome Obesity Targets Therapy, 4: 409-416.

DOI: $10.2147 / \mathrm{DMSO} . S 24221$

Sarri, K.O., S. Higgins and A.G. Kafatos, 2006. Are religions "healthy"? A review of religious recommendations on diet and lifestyle. Ecol. Culture Nutrit. Health Dis., 14: 7-20.

Temizhan, A., I. Tandogan, O. Donderici and B. Demirbas, 2000. The effects of Ramadan fasting on blood lipid levels. Am. J. Med., 109: 341-342. DOI: $10.1016 / \mathrm{S} 0002-9343(00) 00498-8$

Whiting, T.L., 2007. The United States' prohibition of horsemeat for human consumption: Is this a good law? Canadian Vet. J., 48: 11731180.

WHO, 2015a. World Health Organization Obesity and overweight.

WHO, 2015b. Global Health Observatory (GHO) Data: Overweight and obesity.

Yusuf, S., S. Hawken, S. Ounpuu, L. Bautistica and M.G. Franzosi et al., 2005. Obesity and the risk of myocardial infarction in 27000 participants from 52 countries: A case-control study. Lancet, 366: 1640-1649. DOI: 10.1016/S0140-6736(05)67663-5

Zeen, R., 2011. Report on Freedom of Thought and Creativity. 